\title{
FOCO DE MALÁRIA NO ESTADO DE SÃO PAULO (BRASIL)*
}

\author{
José Carlos Rehder de Andrade ** \\ Carlos Frederico Dantas Anjos** \\ Dalva Marli Valério Wanderley * * \\ Maria José Chinelatto P. Alves* * \\ Paulo Cesar de Campos **
}

\begin{abstract}
ANDRADE, J.C.R de et al. Foco de malária no Estado de São Paulo (Brasil). Rev.Saúde públ., S.Paulo, 20: $323 \cdot 6,1986$.

RESUMO: Assinala-se foco de malária instalado no período de fevereiro a abril de 1984, no Estado de São Paulo, Brasil. A transmissão teve início a partir de fonte de infecção desconheciđa, em área periurbana do municipio de Panorama. Foram diagnosticados 10 casos, todos devidos a Plasmodium falciparum, variando o intervalo entre o aparecimento dos sintomas e o diagnóstico de 2 a 22 dias, tendo sido encontradas duas espécies transmissoras da malária: Anopheles $(N)$ darlingi e Anopheles(N) albitarsis. São descritas a medidas que levaram à eliminação do foco destacando-se a detecção de um caso através da coleta de lâminas de investigação (gota espessa) entre 1236 morađores da área. $O$ aparecimento desse foco permitiu avaliar o risco potencial da reintrodução da malária no Estado de São Paulo e intensificar as medidas de vigilância epidemiológica em áreas vulneráveis/receptivas.
\end{abstract}

UNITERMOS: Malária, prevenção e controle. Malária, ocorrência. Plasmodium falciparum. Insetos vetores. Anopheles (N.) darlingi. Anopheles (N.) albitarsis. Vigilância epidemiológica.

\section{INTRODUÇÃO}

A análise da situação do "Programa de Erradicação da Malária" no Estado de São Paulo foi objeto de trabalho anterior 7 , onde os autores alertam para o risco potencial de reintrodução da endemia em áreas do território paulista, em conseqüência da mobilidade de doentes de malária, oriundos principalmente da Região Amazônica. Com o aumento do número de casos notificados em 1983, no Estado de São Paulo7, e principalmente no Brasil 3 , era de se esperar que em áreas livres da endemia, mas com presença de mosquitos vetores, associados a considerável mobilidade populacional, a transmissão pudesse se instalar.

Assim, no início do mês de fevereiro de 1984 , um foco de malária por Plasmodium falciparum foi detectado no município de Panorama, situado no extremo oeste do Estado, as margens do Rio Paraná.

\section{Origem e Delimitação do Foco}

No dia 16 de fevereiro de 1984 , uma criança de três anos, do sexo masculino, moradora da localidade Vila Marrecas, município de Panorama, teve confirmado o diagnóstico de malária. $\mathrm{O}$ exame microscópico demonstrou a presença de Plasmodium falciparum no sangue do paciente, tendo sido, no mesmo dia, iniciado tratamento. A referida criança vinha apresentando febre desde o dia 10 de fevereiro, com diagnóstico a esclarecer, o que motivou o seu deslocamento para o municipio de Dracena, onde permaneceu internada após a confirmação do caso. Por meio de investigação epidemiológica concluiu-se que a transmissão teria ocorrido na localidade do município de residência.

Nos dias 14 e 15 de fevereiro permaneceu internado em hospital, do municipio de Dracena, um paciente do sexo masculino, comerciante, 56 anos, que vinha apresentando febre desde o dia 9 de fevereiro. O mesmo teve alta hospitalar, sem que houvesse suspeita de malária. Ao mesmo tempo, duas pessoas, 36 e 53 anos, ambas domésticas, sexo feminino, por apresentarem quadro febril, foram internadas em hospital do município de Tupi Paulista recebendo, também, alta hospitalar sem diagnóstico esclarecido. Portanto, quando da identificação do primeiro caso de malária, 3 outros pacientes já estavam apresentando sintomatologia caracteristica, com passagens por hospitais sem que se suspeitasse da doença. Posteriormente, verificou-se que quando da detecção do primeiro caso, 7 outros pacientes já estavam apresentando sintomas de malária na localidade de Vila Marrecas. Destes, 3 doentes do sexo feminino, com idade superior a 30 anos, domésticas, uma menor, estu-

* Trabalho apresentado no XXI Congresso da Sociedade Brasileira de Medicina Tropical, São Paulo, 1985.

* Da Superintendência de Controle de Endemias (SUCEN) da Secretaria de Estado da Saúde - Rua Paula Souza, 166 - 01027 - Sāo Paulo, SP - Brasil. 
dante e 2 outros casos, sexo masculino, com idade de 18 e 26 anos, respectivamente oleiro e lavrador.

Diante dos casos indicadores da transmissão em Vila Marrecas, foi iniciado um trabalho de delimitação do foco. Assim, de acordo com as normas técnicas do Programa de Erradicação da Malária, do Estado de São Paulo, todas as casas situadas num raio de $5 \mathrm{Km}$ a partir da residência do primeiro paciente, foram consideradas como pertencentes à área do foco, para fins de busca de casos, estudos entomológicos e operações de inseticidas.

\section{Descriçāo da Area Geográfica}

O município de Panorama, pertence a Região Administrativa de Presidente Prudente, localizada no extremo oeste do Estado de São Paulo (Figura).
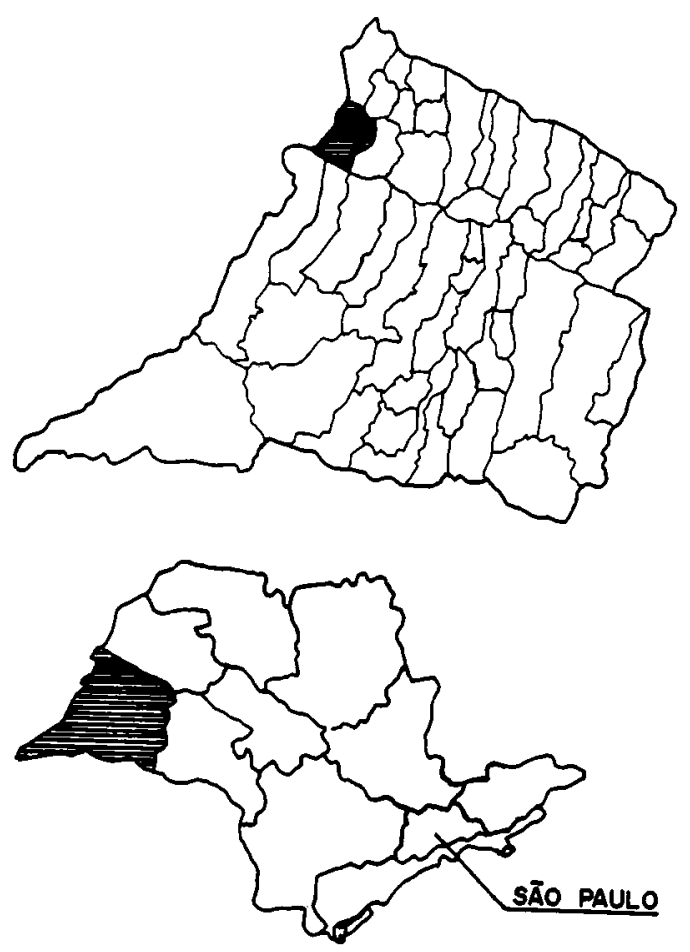

Figura - Localização do município de Panorama, Estado de São Paulo.

Este município situa-se na parte norte daquela região, na denominada microregião Nova Alta Paulista, limitando-se ao norte com o município de Paulicéia e Santa Mercedes, ao sul com os municípios de Caiuá e Presidente Epitácio, a leste com o município de Ouro Verde, e a oeste com o Estado do Mato Grosso do Sul (município de Brasilândia), tendo como divisa o Rio Paraná. Apresenta uma população estimada de 8.712 habitantes para o ano de 1984, com uma taxa de crescimento anual de 2,10 e uma taxa de urbanização de 71,182. A área do foco, localidade Vila Marrecas, apresenta um grande número de casas aglomeradas, conferindo-lhe características de periferia de cidade, com melhoramentos do tipo calçamento das ruas e luz elétrica. E ladeada pelo Córrego das Marrecas com 4 a $5 \mathrm{~m}$ de largura, que desemboca no Rio Paraná, formando uma represa natural. A localidade. dista aproximadamente $2 \mathrm{Km}$ do centro da cidade de Panorama, possuindo uma estação ferroviária da linha Paulista, que liga os municípios de Panorama, Adamantina, Marília e São Paulo. Estima-se que 1.800 pessoas residam na localidade.

\section{Movimentos Populacionais}

O município de Panorama é considerado turístico na Região, possuindo um "camping" freqüentado por turistas procedentes de diversos estados do País. E freqüente o trânsito de pessoas vindas de outras áreas, principalmente através da estrada de ferro e de barcos que ligam o municipio ao Estado de Mato Grosso do Sul.

0 Córrego das Marrecas é freqüentado por crianças, lavadeiras e pescadores, sendo estes últimos uma constante em todos os municípios próximos ao Rio Paraná.

\section{Medidas Aplicadas Para Eliminar o Foco}

As providéncias tomadas pela SUCEN (Superin. tendência de Controle de Endemias) para debelar o foco de Vila Marrecas podem ser reunidas em três grupos: operaçð̄es de inseticida, atividades epidemiológicas e pesquisas entomológicas.

A partir de 28 de fevereiro de 1984, foram rociadas 518 residências na área do foco com DDT pó molhável a $75 \%$. Foi realizada também uma aplicação de nebulização térmica com Baygon Swing Fog, com o objetivo de diminuir a densidade de mosquitos alados.

Procedeu-se à busca de casos, ao diagnóstico laboratorial das amostras de sangue colhidas no campo, ao tratamento dos positivos e à investigação epide. miológica dos casos.

Por meio da coleta de Lâminas de Investigação de Casos (LIC) foi processada a busca de casos, realizada em toda a população residente na área do foco, pelos funcionários da SUCEN, em visitas domiciliares. Foram colhidas e examinadas 1.236 amostras de sangue, resultando num caso positivo, cuja paciente permaneceu 20 dias com sintomas de malária e com dois episódios de internação hospitalar, no município de Tupi Paulista. O exame da amostra apresentou apenas gametócitos de P.falciparum.

Tendo em vista que ao serem iniciadas as operações de campo, 6 casos já estavam confirmados, o diagnóstico laboratorial passou a ser realizado na própria área do foco, a fím de que as investigações 
e tratamento pudessem ser agilizados, visando a detecção precoce de novas fontes de infecção.

Quanto ao tratamento dos casos, foi empregado sulfato de quinino na dosagem de 25 a $35 \mathrm{mg} / \mathrm{Kg}$ de peso/dia por 3 dias e tetraciclina, $1 \mathrm{~g} /$ dia durante 7 dias.

Com relação a investigação epidemiológica dos casos diagnósticados, 6 foram do sexo feminino, domésticas, exceto uma de 13 anos estudante e as demais com idades acima de 30 anos e 4 do sexo masculino, uma criança de 3 anos e os outros com idade acima de 18 anos (lavrador, comerciante e oleiro). $O$ intervalo entre o aparecimento dos sintomas e o diagnóstico variou de 6 a 22 dias, em 9 doentes. $O$ último caso registrado na localidade ocorreu 52 dias após o início dos sintomas do primeiro. Com exceção do caso detectado através da coleta de LIC, todos os outros foram diagnosticados através da busca passiva.

Apenas um dos pacientes não residia na localidade, porém freqüentava o Córrego das Marrecas constantemente, com a finalidade de colocar arma. dilhas para caça e pesca.

O acompanhamento epidemiológico do foco foi feito através da Busca Ativa quinzenal no primeiro mês, seguido de coleta mensal por um período de um ano.

Quando do início das atividades epidemiológicas no foco, foram realizados contatos com hospitais e centros de saúde da região, com o objetivo de divul. gar a malária, visando à notificação precoce dos casos febrís. Ao mesmo tempo, foram distribuídos folhetos educativos sobre a endemia em pontos estratégicos: postos de serviço em rodovias, balsas, pontes, entre outros.

Em pesquisas realizadas, tanto no intra como no extra-domicílio, foi constatada a presença de exemplares de Anopheles (N.) darlingi e Anopheles (N.) albitarsis.

\section{COMENTÁRIOS}

Quando do inicio das atividades do "Plano de Erradicação da Malária"4 no Estado de São Paulo, em 1960, o município de Panorama foi incluído na denominada Área em Ataque, a exemplo de outros municípios situados às margens dos Rios Grandes e Paraná. Desta forma, todos os domicílios existentes foram submetidos a ciclos semestrais de rociado com DDT pó molhável a $75 \%$ e os seus moradores examinados através de Busca Ativa (exame microscópico do amostras de sangue de todos os indivíduos com febre atual ou recente), com posterior tratamento dos casos confirmados. O município de Panorama, permaneceu em fase de Ataque até o ano de 1973. Entre 1968 e 1973 não foram registrados casos autóctones no município, passando o mesmo a integrar, em 1974, a Ârea em Consolidação do Estado, muito embora as operações de rociado tenham sido suspensas em 1968 , tendo permanecido como prática rotineira a realização de Busca Ativa, com periodicidade mensal6. A permanência de Panorama em fase de Ataque, por um período maior que o preconizado pelo modelo inicial do Programa, ou seja, exterminar a enfermidade em cinco anos, utilizando o DDT como arma quase que exclusiva 1 , pode ser considerado como exemplo de que a erradicação da malária no Estado de São Paulo não dependeria apenas de fatores de ordem tecnológica.

A 69 Avaliação do Programa5, realizada em 1980 , transferiu o município para a fase de Manutenção, o que corresponde a ações de vigilância epidemiológica. Esta avaliação, a última realizada no Estado de São Paulo, considerou como ponto funda. mental para a transferência do município para a fase mais avançada do Programa, a ausência de transmissão nos últimos três anos. Dois fatores de grande importância foram colocados em plano secundário na ocasião, ou seja, deslocamentos populacionais para a Amazônia Legal realizados através dessa Região do Estado e o aumento do número de casos de malária diagnosticados no País, a partir dos anos setenta.

Neste surto epidêmico não foi possível detectar a fonte introdutora da malária. Hipóteses podem ser levantadas a esse respeito, tais como a presença de pessoas atraídas para a atividade de pesca, muito freqüente na área, ou de indivíduos, de procedências ignoradas, que permaneciam na Estação férrea da localidade, a espera de auxílio para prosseguir viagem. De qualquer forma, muitas vezes a vigilância epidemiológica não consegue detectar a origem da transmissão, contudo algumas evidências indicam os pontos mais vulneráveis, que necessitam ser acionados com maior intensidade pelas atividades de controle.

Em relação às medidas de controle realizadas, dois aspectos merecem ser ressaltados. A realização de coleta de lâminas de sangue de toda a população da localidade, independente de apresentarem estado febril (LIC), possibilitou a identificação de um caso positivo apenas com gametócitos de P.falciparum. Assim, recomenda-se que em áreas com presença de vetor domiciliar Anopheles darlingi, a busca de casos deva ser efetuada em toda a população presente, estendendo a prática a outras localidades caso a situação epidemiológica aponte essa necessidade. Outro aspecto, diz respeito a aplicação de nebuliza. ção térmica com Baygon Swing Fog, que diminuin. do a densidade de alados, deve ter contribuido para que o foco não assumisse proporções maiores. Tal medida, não preconizada nas normas técnicas ini- 
ciais do Programa, deve ser incluida em área com apreciável densidade demográfica.

A ocorrência desse episódio em Panorama serviu de alerta à SUCEN, com relação as áreas mais propícias a instalação de focos de transmissão no Estado. Assim, a partir de março de 1984, todos os municípios situados às margens do Rio Paraná, indepen. dente da fase do programa que se encontravam, passaram a constituir "Área de Vigilância Intensiva".
Desse modo, as localidades situadas em uma faixa de $5 \mathrm{Km}$ ao longo do Rio Paraná, começaram a ser visitadas mensalmente pelas equipes de campo da SUCEN, com vistas a procura de febrís e a divulgação da malária. Este último aspecto foi intensificado em todo o Estado, principalmente junto a categoria médica, onde a suspeita clínica de malária deve ser uma constante, em todos os pacientes procedentes de áreas endêmicas do Brasil.

\footnotetext{
ANDRADE. J.C.R. de et al. [Malaria focuses in S.Paulo State (Brazil)] Rev.Saúde públ., S.Paulo, 20: $323 \cdot 6,1986$
}

ABSTRACT: The malaria focus which ocurred in the State of S.Paulo, Brazil, in the period from February to April 1984, is analysed. The transmission began at an unknown source of infection in an outlying area of Panorama county. Ten cases caused by Plasmodium falciparum were diagnosed. The interval between appearance of the symptoms and the diagnosis varied from 2 to as much as 22 days. Two species responsible for malaria transmission were found in the surveys: Anopheles (N.) darlingi and Anopheles (N.) albitarsis. The steps that led to the elimination of the focus are described, highlighting the detection of one case by means of the investigation slides (thick blood film) of 1,236 inhabitants of the area. The appearance of this focus was of great importance as a means of assessing the potential risk of the reintroduction of malaria into S.Paulo State. Epidemiological surveillance measures must be intensified in vulnerable/receptive areas.

UNITERMS: Malaria, prevention and control. Malaria, occurrence. Plasmodium falciparum. Insect vectors. Anopheles (N.) darlingi. Anopheles (N.) albitarsis. Epidemiologic surveillance.

\section{REFERENCIAS BIBLIOGRÁFICAS}

1. AGUDELO, S.F. Os processos sócio-econômicos na transmissão e no controle da malária. Rev.bras.Malar., $35: 89-100,1983$.

2. FUNDAÇÃO SEADE. Regiāo de Presidente Prudente: vinte anos de alta evasão populacional. São Paulo, 1983. (Análise Demográfica, 11).

3. INFORME EPIDEMIOLOGICO SUCAM. (Superintendência de Campanhas de Saúde Pública). Brasília, 2 (14), 1983.

4. SECRETARIA DA SAÛDE. Serviço de Profilaxia da Malária. Plano para a erradicação da malória no Es. tado de São Paulo, Brasil. São Paulo, 1958.

5. SECRETARIA DA SAUDDE. Superintendência de Controle de Endemias (SUCEN). Avaliaçâo epide. miológica do programa de erradicaçāo da malária:
São Paulo. Transferência de manutenção Serviços Regionais 2, 8, 9 e 10. São Paulo, 1980.

6. SECRETARIA DA SAÜDE. Superintendência de Controle de Endemias (SUCEN). Relatónio de avaliação do programa de erradicaçäo da malária - 1963/681 71/73. São Paulo, 1981.

7. WANDERLEY, D.M.V. et al. Malária no Estado de São Paulo, 1980 a 1983. Rev.Saúde públ., S.Paulo, $19: 28 \cdot 36,1985$.

Recebido para publicação em 08/11/1985

Reapresentado em 26/06/1986

Aprovado para publicação em 27/06/1986 